\title{
REFLECTIONS ON FREI OTTO AS MENTOR AND PROMOTER OF SUSTAINABLE ARCHITECTURE AND HIS COLLABORATION WITH KENZO TANGE AND OVE ARUP IN 1969
}

\author{
Juan G. OLIVA SALINAS ${ }^{1}$, Marisela MENDOZA, ${ }^{2}$ and Edwin GONZÁLEZ MEZA ${ }^{3}$ \\ ${ }^{1}$ Professor, Universidad Nacional Autónoma de México, Mexico City, jgos@unam.mx \\ 2 Senior Lecturer, Nottingham Trent University, Nottingham, UK, marisela.mendoza@ntu.ac.uk \\ ${ }^{3}$ Full-time Professor, Universidad de las Américas Puebla, San Andrés Cholula, Puebla, Mexico, edwin.gonzalez@udlap.mx
}

Editor's Note: This space reserved for the Editor to give such information as date of receipt of manuscript, date of receipt of revisions (if any), and date of acceptance of paper. In addition, a statement about possible written discussion is appended.

DOI: Digital Object Identifier to be provided by Editor when assigned upon publication

\section{ABSTRACT}

The present paper will discuss through personal accounts from Professor Juan Gerardo Oliva Salinas who was a doctorate student in Stuttgart from 1977-1982 the ingenious and sui generis persona of Frei Otto and his contributions to promote the design and construction of sustainable lightweight structures and which without doubt together with his academic and professional accomplishments took him to win the Pritzker Architecture Prize in 2015. The paper will also discuss the 1969 Kuwait Sports Centre Competition, which was the first project in which Kenzo Tange, Frei Otto and Ove Arup worked together and which can be considered as a prelude to the seminal project 'Artic City' in 1971.

Keywords: Frei Otto, sustainability, lightweight structures, IL, SFB 64, Kenzo Tange, Ove Arup, Félix Candela, Pier Luigi Nervi

\section{INTRODUCTION}

The thinking and ideas of Frei Otto and his enigmatic personality are not easy to describe. Frei Otto was a conscientious man, with clear and precise ideas of what sustainable architecture and engineering should be (Figure 1). However, the term Sustainability was not in common use at that time as it is today.

In October 1976, Juan Gerardo Oliva, then a doctoral scholarship student of the German Academic Exchange Department (DAAD - Deutscher Akademischer Austauschdienst) had his first meeting with the renowned and admired Professor Frei Otto at the Lightweight Structures Institute (IL - Institute für leichte Flächentrag-werke), at the University of Stuttgart in Germany. The purpose of the meeting was to request authorisation from Professor Otto to develop at the IL the research work committed to with the DAAD regarding: "the electronic calculation of lightweight structures."

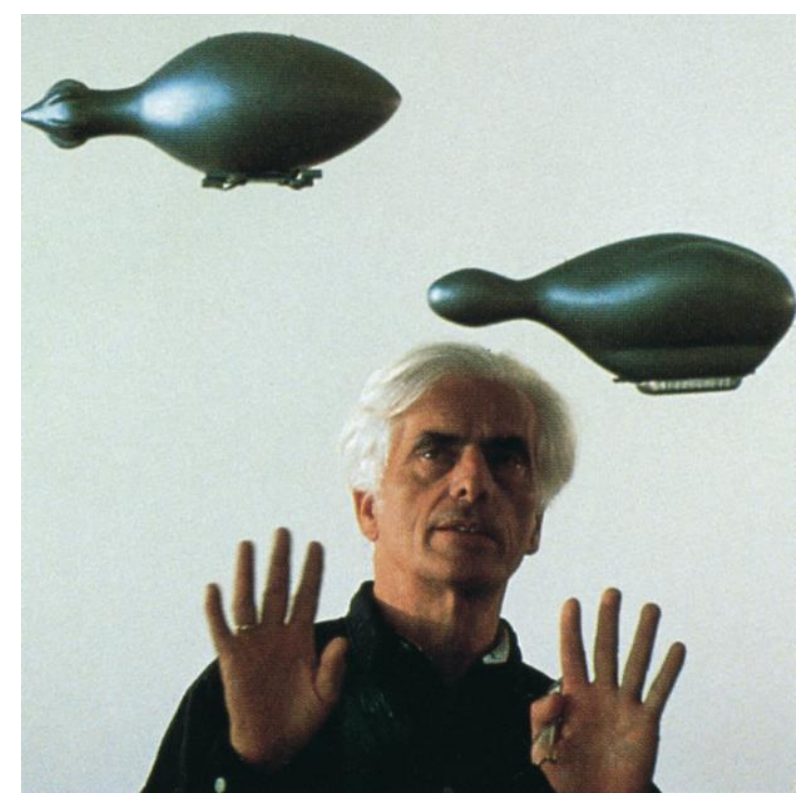

Figure 1: Frei Otto: ingenious and sui generis persona [Photo: IL-Archive, University of Stuttgart, Germany]

Professor Otto's response was clear and blunt, work on the design of the lightweight structures that were 
created at the IL were developed primarily with the preparation of physical models. These models had to be carefully and skilfully crafted, as they had to represent the architectural form designed and represent the actual mechanical behaviour of the structural system. In addition, the physical model had to provide the initial geometry that all the other work groups would use: civil engineers, architects, geodesists, chemists, etc., who would perform the necessary complementary studies for the execution of works and the relating mechanical calculations with the support of computer programs.

Based on the reasons described above, it was clear that the work place of Juan Gerardo Oliva at that time was not the IL. Professor Otto prompted him to work in other institutes within the University of Stuttgart and if after at least one year he still had the scholarship and the desire to work at the IL, then he could come back to work with him in his work group; which is what happened subsequently.

\section{FREI OTTO AND THE SFB 64}

Cooperative Research Group 64 (SFB 64 Sonderforschungsbereich 64) "Wide-Span Surface Structures" ("Weitgespannte Flächentragwerke") was set up by a group of institutes sponsored by the University of Stuttgart and the German Research Community (DFG - Deutsche Forschungsgemeinschaft). SFB 64 was made up of institutes in four disciplines: Architecture, Civil Engineering, Geodesy and Aerospace Technology.
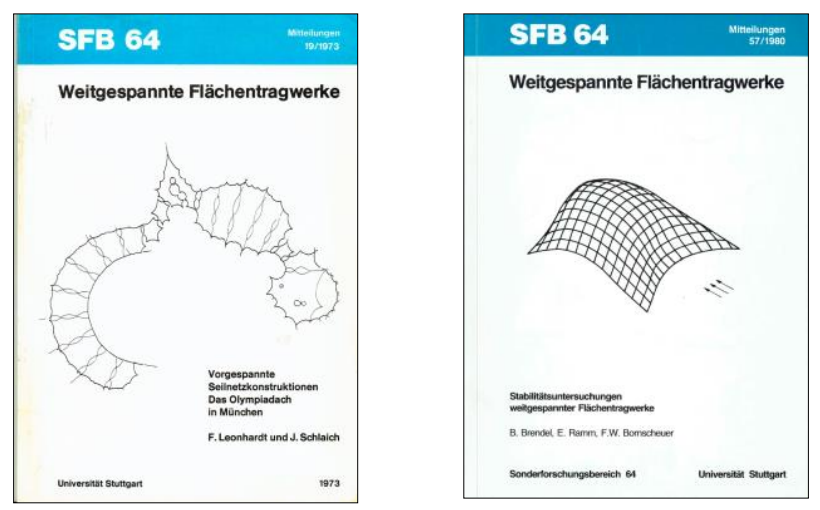

Figure 2: SFB 64 publications: $19 / 1973$ and 58/1980 at the University of Stuttgart

From 1970 and through the group that had already been established, meticulous and precise research work was embarked on regarding the problems arising from the planning, execution and use of widespan surface structures. Two examples of SFB 64 publications are shown on Figure 2.

The names of all the professors, doctors and researchers who made up SFB 64 were known as persons of unquestionable skill and productivity each in their own disciplines. However, the indisputable leader of all of them was Frei Otto.

It was from him that the initial ideas for each new project arose and which were subsequently developed, improved and complemented by all of the other members of SFB 64. This was a characteristic that architect Félix Candela recognised during his attendance of the 2nd International Symposium "Wide-Span Surface Structures" ("Weitgespannte Flächentragwerke"), held from 14 to 18 May 1979 at the University of Stuttgart.

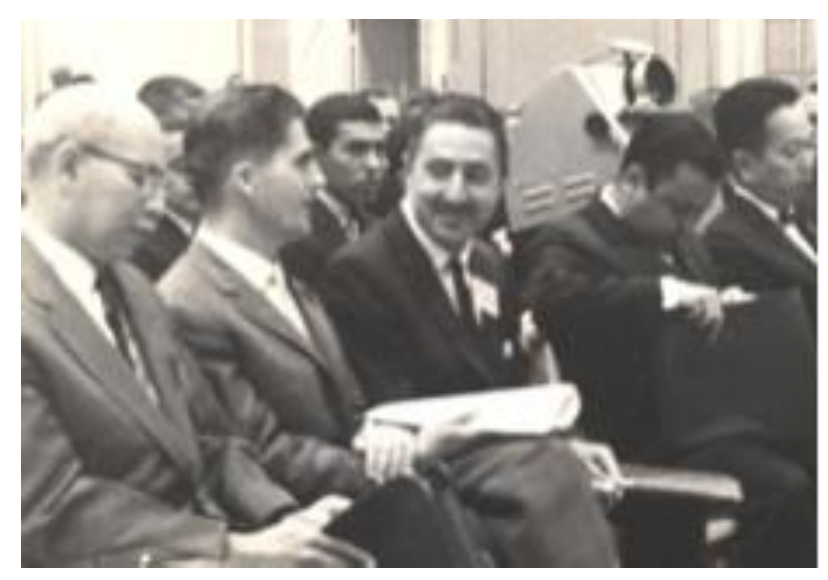

Figure 3: Frei Otto and Félix Candela, an old friendship from previous Symposia

Félix Candela was invited to give an improvised talk during the closing ceremony of the Symposium at which he said: ".. there is no doubt in our case that Frei Otto is this kind of personality and that lightweight structures would not be at this stage of development, this wonderful blooming, if he had not 
devoted to them his tireless work and his admirable tenacity. I feel very close to him, because we have been in similar situations, trying to develop and promote unusual structures, but I did not have his ability to put together a team of devoted and talented people, helping him to develop his ideas and to publish generously the results for general information. Therefore, my contribution has been much more limited." [1] (Figure 3).

During the period of Juan Gerardo Oliva's studies at the University of Stuttgart from 1977 until the end of 1982, as a DAAD scholarship student, Professor Ekkehard Ramm acted as his academic tutor. Ekkehard Ramm was continuously involved with the SFB 64 and the IL and when Frei Otto retired as a professor of the University of Stuttgart in 1990, Ramm was at the helm of the IL for over five years.

In addition to taking part in the IL, Oliva had the opportunity to perform his research work at two other institutes, which, together with the IL, made up part of SFB 64: The Institute for Applications of Geodesy to Engineering (IAGB - Institut für Anwendungen der Geodäsie im Bauwesen), led by professor Klaus Linkwitz and the Institute of Model Statics (IMS - Institut für Modellstatik), led by professor R.K. Müller (Figure 4).

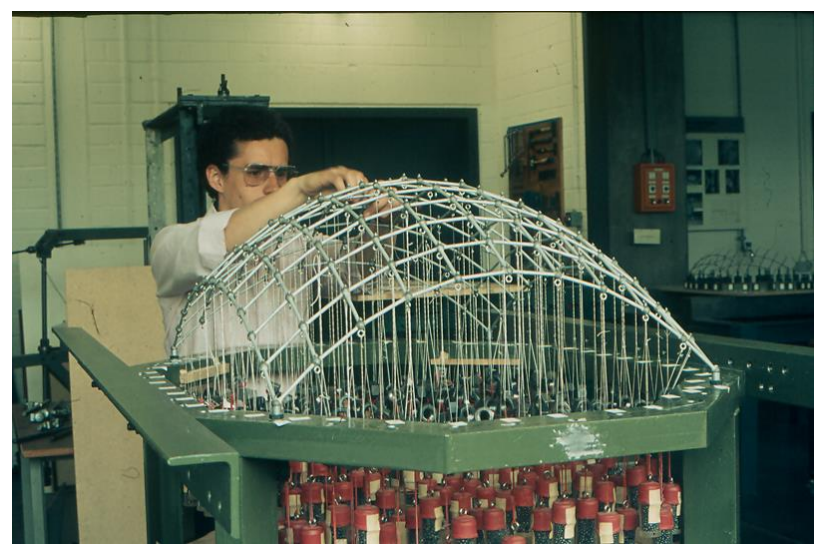

Figure 4: Juan Gerardo Oliva working at the IMS at the University of Stuttgart, 1980

During his time at these institutes, Oliva had the opportunity to observe how Frei Otto's original ideas were transferred to other disciplines and research groups. Within these groups, Frei Otto's ingenious ideas could be supplemented, probed further into, developed and implemented and thus generate innovative proposals for lightweight structures, as Félix Candela remarked at the time.

\subsection{Teaching and research at the IL}

Frei Otto did not usually teach classes to a group of architecture students in the classrooms of Building $\mathrm{K} 1$, situated in the centre of the city of Stuttgart, where the Faculty of Architecture and Urban Planning was located. The students that enrolled in his seminar at the IL in Vaihingen, situated in the suburbs of Stuttgart, had to read the material published by the Institute itself for two weeks before starting and then joined the work group to support the current research projects at the IL. In the case of Juan Gerardo Oliva, his integration in the IL was different. Frei Otto and the IL provided Oliva with the necessary support for him to carry out the research work required to complete his doctoral thesis entitled "About the Construction of Grid Shells" ("Über die Konstruktion von Gitterschalen".) [2] (Figure 5).

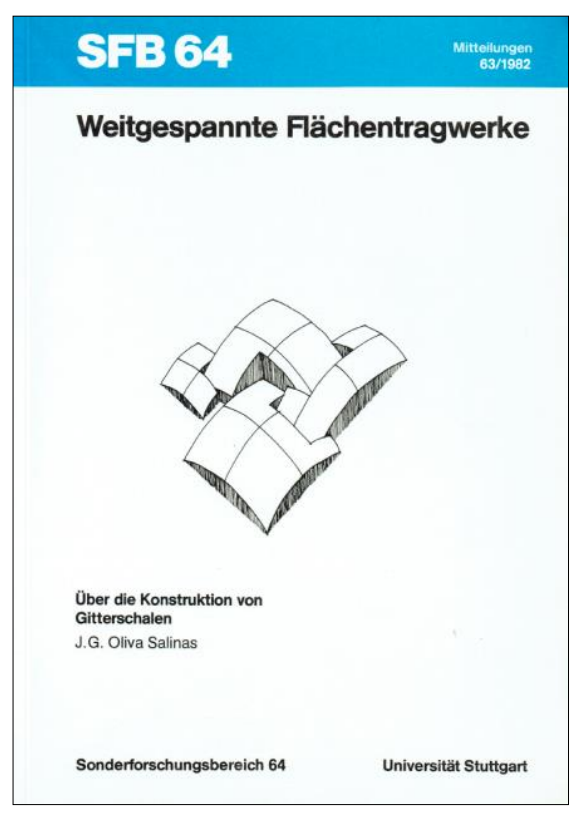

Figure 5: Doctor work of Juan Gerardo Oliva: SFB 64, Mitteilungen 63/1982 at the University of Stuttgart

Grid shells were the structural system selected by Oliva because he believed that he could develop contributions to improve the design and construction processes of these structures. The process to determine the form of the grid shells until that time involved the meticulous and careful preparation of a physical measurement model, based on a scale model of hanging nets which hung from a given edge, corresponding with the architectural design of the shell [3]. 
Frei Otto demanded a high level of perfection in the preparation of the measurement models, as those models would then be placed on the measuring table that he designed himself (Figure 6). From that table hung a plumb line that could be moved in directions " $x$ ", " $y$ " and " $z$ " electronically. Once the plumb line had been located exactly above each of the nodes of the hanging net, a button was pressed to print the values of each of the three coordinates on a strip of paper. The printer was the same as those used to send telegrams using telex. At the same time, the plan of the grid shell was drawn on a piece of paper fixed to the plate on the upper part of the measuring table.

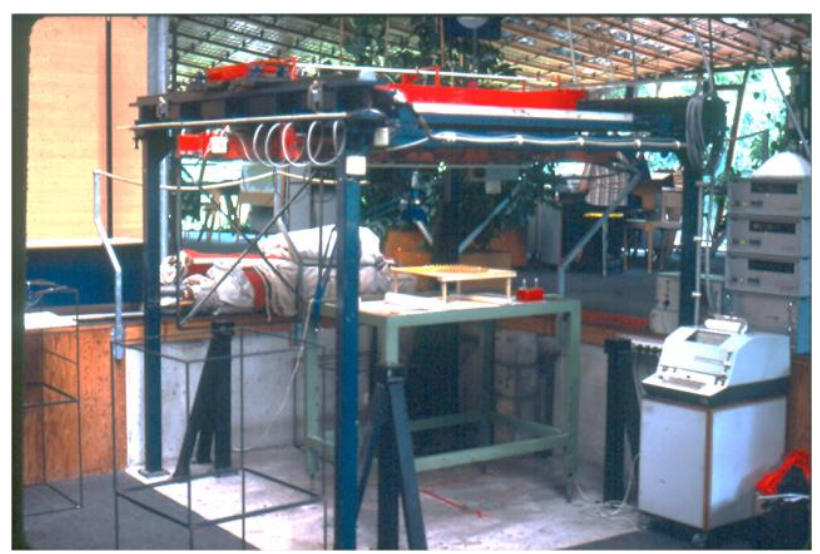

Figure 6: Internal view of the IL, showing the measuring table, 1980

It is important to remember that at the end of the Seventies, the first desktop computers were just starting to emerge and at the IL, there were only electric typewriters rather than desktop computers.

Based on the exhaustive work required and the long times necessary to execute the grid shell formfinding and measurement processes, Oliva developed an innovative proposal for form-finding, in which the making of a measurement model is not required. These are specific cases in which the hanging net is generated by the translation of one catenary onto another. This arose out of the following idea: if a translation surface is generated in which the directrix is a catenary and the generatrix is another catenary, which are mutually orthogonal, the result would be equivalent to a hanging net. Furthermore, if there is a hyperbolic cosine equation that describes the form of a catenary, then the process of form-finding can be performed mathematically and programmed electronically, without the need to build a physical measurement model (Figure 7). Meanwhile, Frei Otto observed with interest Oliva's achievements and asked him to deliver the slides of the material generated on this subject to the IL archive.

As part of his thesis, Oliva programmed a mathematical model called GEOG (GEOmetry-Grid Shell) in FORTRAN IV. GEOG is a parametric programme that allows the generation of the geometry of a translation-grid shell in just a few seconds. It allows the structural designer to generate various possible forms in very little time and without the need to build a physical measurement model.
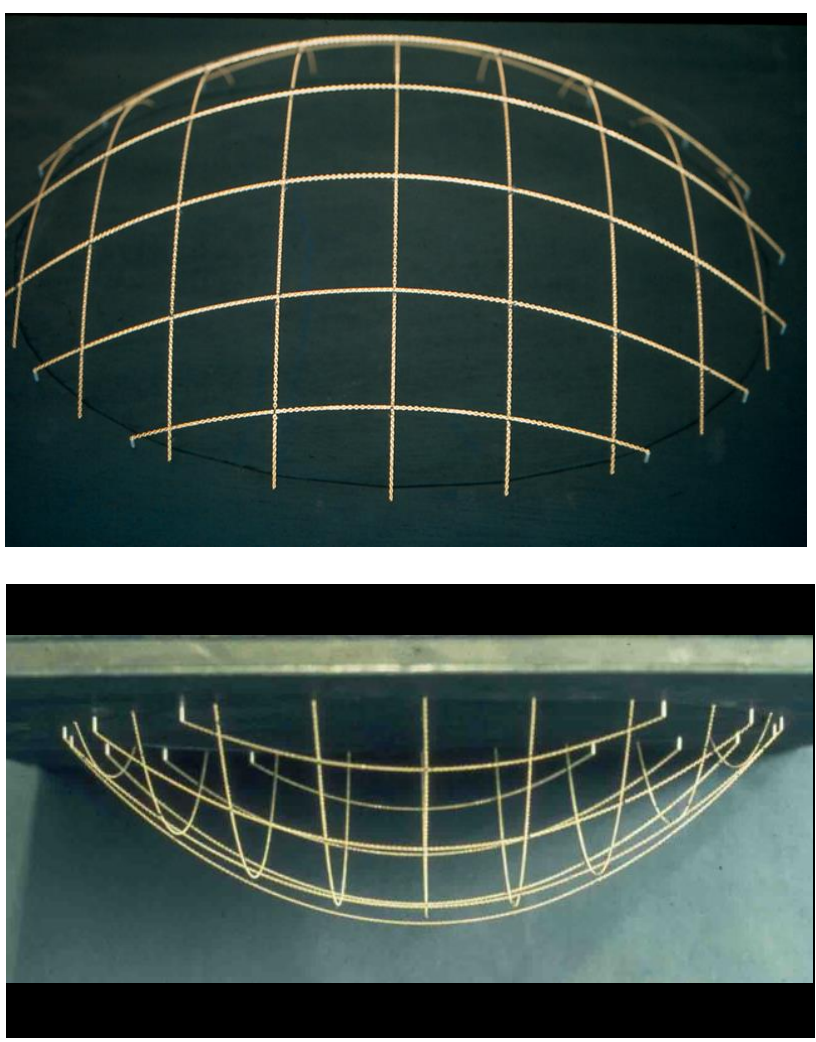

Figure 7: Hanging model of a translation-grid shell, Juan Gerardo Oliva, 1980

Subsequently, Oliva also found other geometric properties of the translation surfaces that aid the design and construction of a grid shell. Among these properties is the option to cover the shells with totally flat plates, as he demonstrated that four adjacent nodes of the grid on the translation surface are coplanar. Therefore, the synclastic curvature of the shell may be covered with completely flat plates in various materials, such as wood, glass, reinforced concrete or aluminium, for example.

In addition, Oliva designed three proposals for universal nodes for this type of structures, whether 
constructed with straight or curved bars. These nodes adapt to any surface node.

Despite the apparent limitation of applying the aforementioned methodology, the legacy of Frei Otto may be appreciated in the design and construction of grid shells in which the versatility that may be achieved is shown. Examples of this are some translation-grid shells designed and constructed from 1984 in Mexico City (Figure 8).
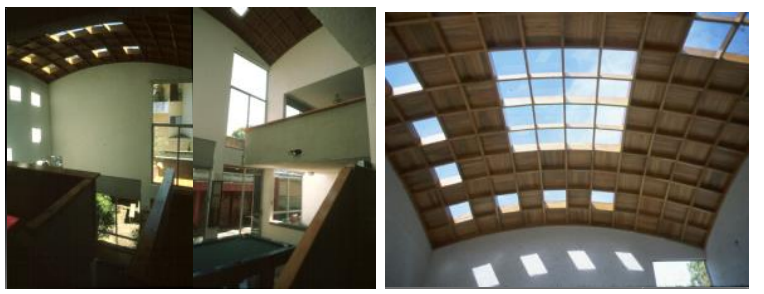

a) One-family house in Mexico City, Juan Gerardo Oliva, 1984
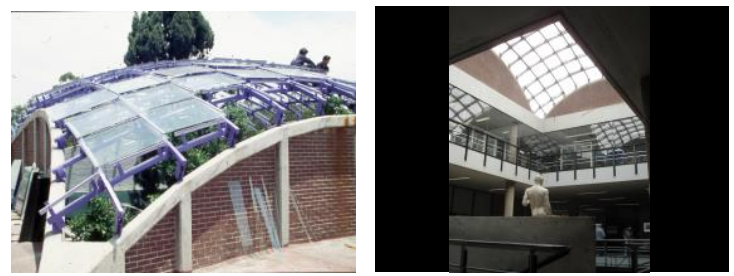

b) Hall of the Faculty of Architecture at University of Mexico, Mexico City, Juan Gerardo Oliva, 1992
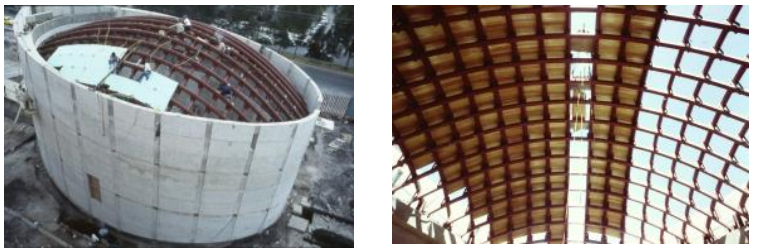

c) Auditorium of the Federal Electoral Tribunal Hall in Mexico City, Juan Gerardo Oliva, 1994
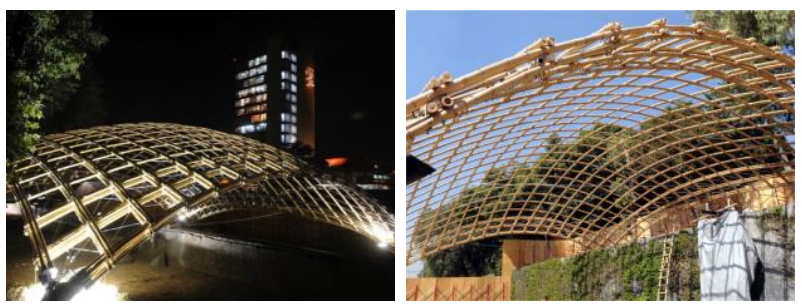

d) Translation-grid shell constructed with bamboos at the University of Mexico, Mexico City, Juan Gerardo Oliva, Andrés Casares and Eder Ademar Hernández, 2011

Figures $8, \boldsymbol{a}, \boldsymbol{b}, \boldsymbol{c}$ and $\boldsymbol{d}$ : Translation- grid shells designed and constructed by Juan Gerardo Oliva and other colleagues
The highly demanding approach of Frei Otto in the preparation of the measurement models also applied to the daily routine of the research and projects developed at the IL. When Oliva considered his physical model complete, Frei Otto observed the work done and requested that he improve it not once, but several times.

Described below is a last anecdote about Frei Otto with Oliva and apparently, something that had not happened previously in the Faculty of Architecture and Urban Planning. Owing to the delay in a flight that would return him to Stuttgart, Frei Otto did not make it to Oliva's doctoral examination. The examination was postponed just when it was supposed to start to the surprise of all those present. Despite what had happened, the following day Oliva celebrated with a few colleagues and friends the, as yet inconclusive, completion of his doctoral studies. Fifteen days later, on 29 June 1982, Juan Gerardo Oliva presented his examination to obtain the grade of Doktor-Ingenieur before a jury made up of Frei Otto, Nikola Dimitrov, Günther Brinkmann and the Dean of the Faculty of Architecture and Urban Planning. The grade that he obtained was the highest one possible, at the suggestion of Frei Otto: "Sehr gut bestanden", just as he had informed Oliva when he finished reviewing his doctoral thesis.

\section{FREI OTTO AND THE IL}

Frei Otto and the IL made up two terms bound together inseparably during the years that the Institute, which he founded in 1964, was led by Otto. Frei Otto was the IL and the IL was Frei Otto. The tensile structure of the IL with its base of steel cables and metal posts was created in 1966 as a prototype to test the feasibility of constructing with this structural system, as the German Pavilion for the 1967 World Exhibition in Montreal, Canada (Figure 9). 


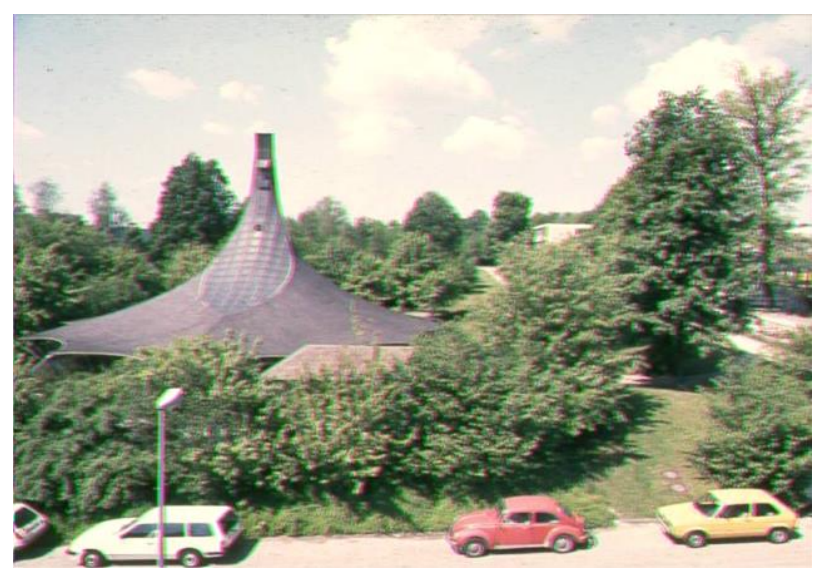

Figure 9: IL, viewed from Juan Gerardo Oliva's cubicle in the University of Stuttgart in 1978

In 1965, a jury headed up by Egon Eiermann assigned the construction of the German Pavilion to Frei Otto and Rolf Gutbrod. The prototype was built in barely three months and was completed in 1966. Frei Otto had the idea that the prototype, which covered a net usable area of approximately $600 \mathrm{~m} 2$, would be suitable and could become the headquarters of his institute if it was transferred and re-erected on University of Stuttgart grounds. After overcoming certain difficulties, this idea became a reality when, in April 1969, it was officially inaugurated as the IL.

In the late Seventies, Juan Gerardo Oliva would observe, from his cubicle on the second floor of a building located opposite the $\mathrm{IL}$, the arrival of professor Otto in his white Mercedes Benz, out of which he would emerge with a black briefcase and with a confident and firm step go into the IL. The large tensile structure that housed the IL was developed in a radial form on a large metal central pole and its interior unfurled to expose a series of desks, chairs and work tables with no dividing walls. Near to the central pole was the measuring table; in front of it, a staircase that led to a mezzanine, where there was a table with some benches along it, which served as a meeting room or for any celebrations.

In an external structure attached to the IL and linked by a covered walkway, was the physical models workshop, which was run by a very kind and likeable character, Mr. Kidaisch. These were the spaces where from 1969 to 1995 , the 41 IL publications were generated that bear witness to the prolific production that arose out of the genius of Frei Otto (Figures 10 and 11).

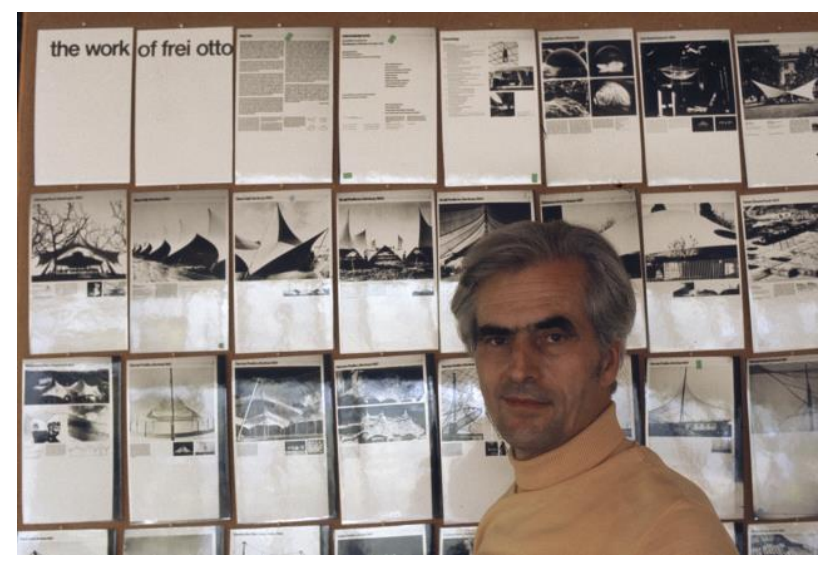

Figure 10: Frei Otto's prolific contributions [Photo: IL Archive, University of Stuttgart]

Otto achieved all of this partly thanks to his sound and enthusiastic work group, which included figures like Jürgen Hennicke, Berthold Burkhardt, Rainer Graefe and Eda Schaur. These are just a few of the names that Juan Gerardo Oliva remembers from the late Seventies, among many others who worked together with them, contributing their work and skill to leave a record of the ideas and developments that arose from and flourished in the IL.
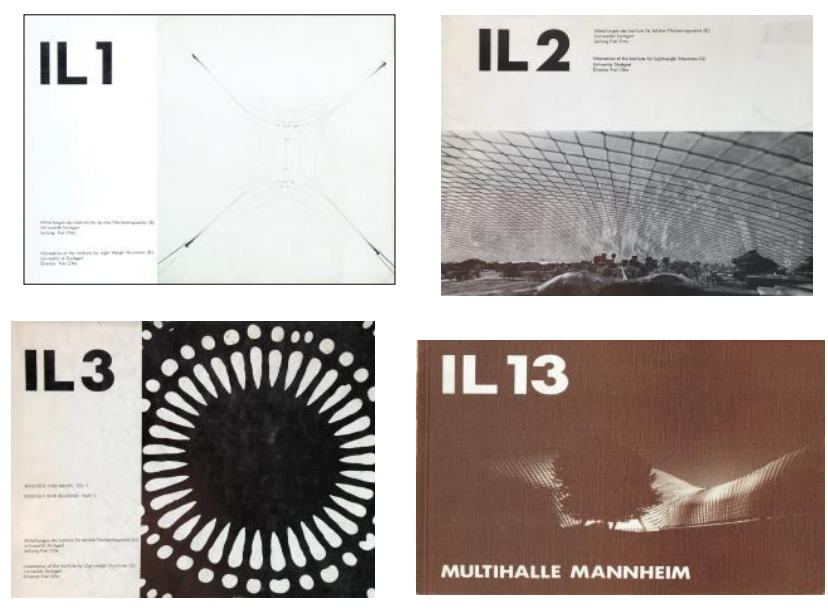

Figure 11: IL publications at the University of Stuttgart, IL 1/197, IL 2/1971, IL 3/1971 and IL 13/1978

\section{PIONEER OF SUSTAINABLE LIGHT- WEIGHT STRUCTURES}

Frei Otto is considered the pioneer of the construction of lightweight structures that started in the mid-twentieth century during the post-war period. Although, the term sustainable development was formalized in 1987 by the Brundtland Report, Otto is considered a pioneer of sustainable structures for a different reason. He complied with the main 
pillars of the 1992 Rio Declaration (economic progress, preservation of the environment, health, social justice, and cultural development). In this manner, he ensured that their proposals encompassed ecological, social, cultural, as well as economic perspectives. His ideas were based mainly on natural structures. This led him to build roofs using wire meshes, pneumatic structures, and reticular shells [4].

From an ecological perspective, his light structures were efficient due to material used. For his projects, he employed only those materials that caused the least amount of waste. This allowed him to create temporary structures that could be recycled, instead of constructing structures that could allow grander roofs. He derived inspiration from natural and biological forms. This approach was demonstrated in a discussion with Engineer Fred N. Severud, in which he criticized the use of luxurious materials, pompous platforms, and monumentality. At the same time, he said that these provide greater weight to the roof. He mentioned the roof suspended by cables between two paraboloids that have been reinforced with concrete by Matthew Novicki, at the Dorton Arena in Raleigh, as an example [5].

From a social perspective, his light structures create new jobs from the beginning of their design process, till their completion and subsequent assembly. But, as mentioned by Jörg Schlaich, they also replace the intellectual effort by the physical effort: the joy of engineering is used instead of the weight. In such an application, the development of technology is truly used for humankind's benefit [6].

From a cultural perspective, he aimed to form his light structures as responsible creations. He achieved this by using a greater architectural sensitivity that he based on his experiences during World War II. He completely rejects the heavy architecture and any symbolic form or prestige architecture that attempt to impose on other styles. However, he does seek to provide a national icon that could create national sentiments. This would help rebuild countries that destroyed by war. In this manner, he implanted a new building culture based on the fundamentals.

From the economic point of view, his light structures sought efficiency in the use of materials and manpower. With this aim, the main function of the structure was to protect and cover users. At the end of World War II, with a damaged economy, this allowed minimization of costs and the consumption of materials in the face of global shortage. This proposal of efficiency and cost reduction would lead to the search of adapting to natural forms of nature with novel techniques.

\section{FACTORS THAT DETERMINE THEIR CONTRIBUTION TO SUSTAINABILITY}

In addition to a design approach to efficiency during design and construction, which allow better economic proposals, Otto's lightweight structures also show a diversity of factors that contribute to the sustainability of his architectural style. The factors that were applied to the decks based on natural forms and techniques stand out as follows: geometry and form, buildings as ephemeral structures, mass of structures, and strength and resistance of their proposals as a parameter in the search for efficiency of their designs.

\subsection{Geometry of natural structures.}

During the study and research of light structures and the search of the right form, Frei Otto explored novel geometric proposals. This resulted in a line of evolution of light roofs; he was searching for different proposals through the understanding of the geometric form progress of the classic form to more complex structures like the natural ones. In the search for the appropriate form, Otto adopted basic concepts, defining forms, the difference between a classical and a complex form, and so on. Later, he observed the evolution of geometries and nature's influence on it. Although, similar to Gropius, he did not look for an architecture based on form, but one based on natural sciences. This is the reason due to which Frei Otto obtained a rational process which included natural laws as a part of the search for the form [5][7]. This understanding of form led him to do further research to understand the structures present in nature. He assumed two references as typologies: living nature and non-living nature.

With regard to structures of non-living nature, they are defined as objects of an inanimate nature. They are formed mainly by celestial bodies or physical processes such as the sun, the flow and movement of fluids, and gases, air and water, the surface tension of liquids and viscous materials such as soap bubbles, and finally, the solidification of materials [4] (Figure 12).

In living nature, objects have an intimate relationship with non-living natural objects, such as fluids and 
gases. These objects are of great importance for the development of life. Living organisms grow, develop, and evolve. These processes imply the need for properties such as elasticity, tensile stress, and development of membranes, such as skin or organisms that lack hard reinforcements, such as worms [4]. Their evolution since their creation has led organisms to a process that would allow them to increase their efficiency and independence to control their environment. This is certainly an important quality for the understanding of human interaction with nature [8].

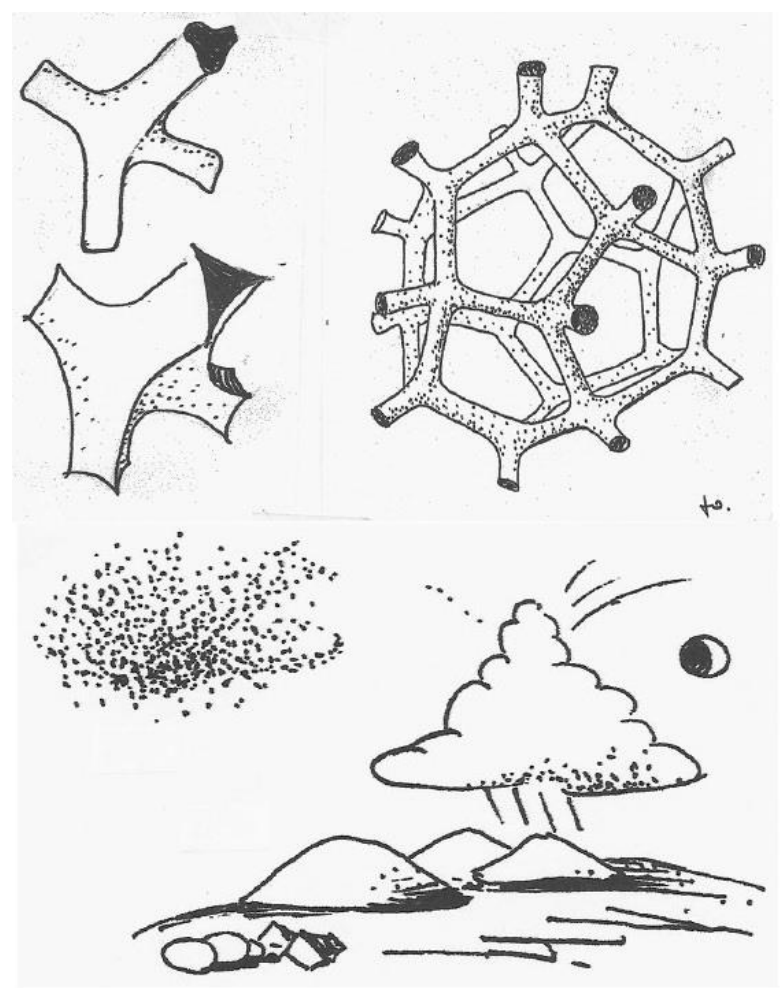

Figure 12: Three-dimensional nets and movement patterns of living and non-living nature [4]

It is precisely this understanding, this phenomenon that occurs between non-living structures and living structures. It guided the experiments Otto later conducted mainly with soap bubbles, soap films, foam, and natural membranes which present surface tension, such as drops of water. With these experiments based on bubbles of soap and foam, Frei Otto became interested in the structures functioning on traction. He was mainly interested in pneumatic structures, cable systems, and networks that create a diversity of forms. He proposed and demonstrated ideas that were consolidated at the beginning of the $21^{\text {st }}$ century. They were also observed with the development of new technologies, the infinite number of geometric proposals that can be achieved through the study of organic structures.

With the bubbles of soap, Frei Otto was able to better understand the behavior of the pneumatic structures. He managed to determine that in each soap bubble the tensions of the membrane are equal at each point in all directions. The soap bubbles always adopt the minimum surface area possible. So, they occupy minimal areas [9]. Taking these concepts as a point of reference, the minimum surfaces do not always form the optimal structural choice. This statement has been made in reference to Frei Otto's experiments with soap films or water-soluble foaming agents: processes in which membranes are supported by tension in two directions, resulting in highly stressed films.

\subsection{Ephemeral and light structures.}

They can be defined as transient or of short duration. So, transience was a characteristic that Frei Otto tried to apply in his structures. This did not seek to build a prestige around his person. It was based on his experiences during World War II, illustrated by his rejection of the idealization of heavy, solid, strong materials and ideals of the National Socialist Germany. The ephemeral term for Frei Otto not only signified dematerialization and energy efficiency, terms sought in current architectural practices. It also implied that his work had an ability to adapt and transform for short periods. This was contrary to the permanent and monumental terms sought by the National Socialist style of architecture [5].

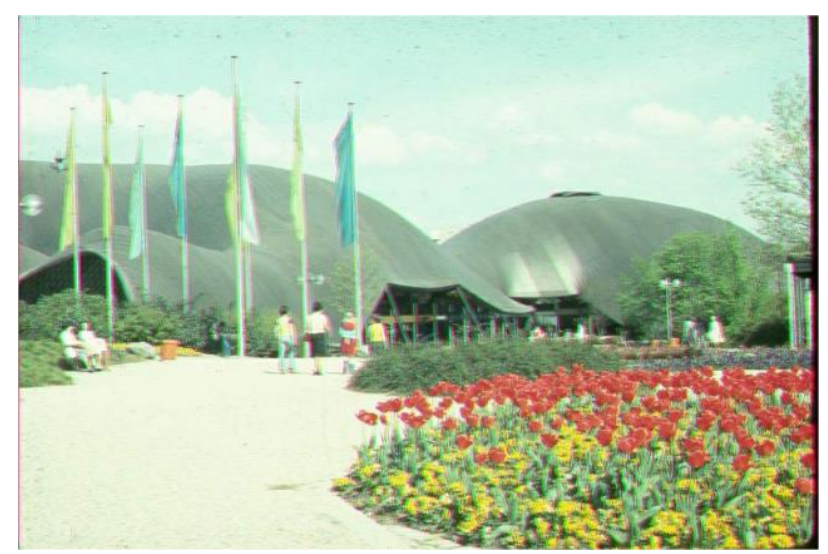




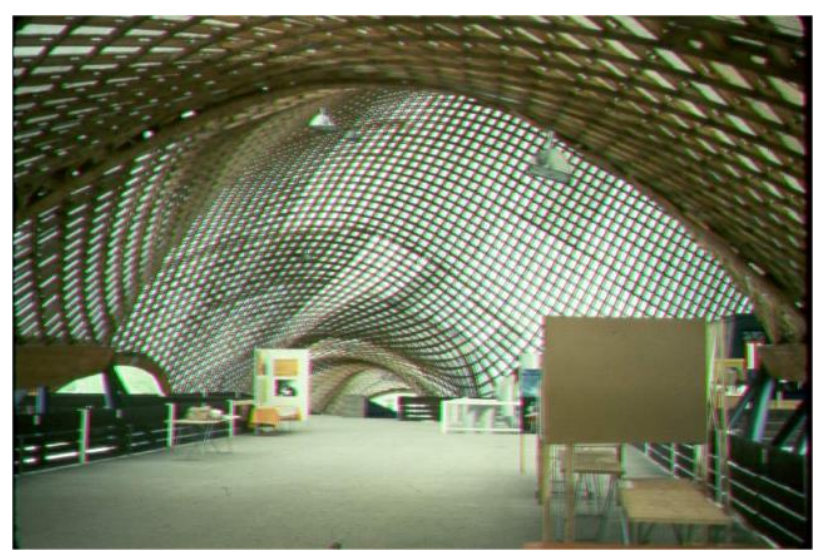

Figure 13: Multihalle Mannheim, Germany, 1975

This way of perceiving architecture through the dematerialization of construction has not been a theme that Frei Otto initiated in the second half of the twentieth century; it began with the Industrial Revolution with the development of new technologies and materials. These were applicable to the construction industry and would be consolidated with the serious political, economic and social crisis created after the culmination of the Second World War. Frei Otto would characterize this dematerialization in his proposals with his philosophy that would develop with a strong social bond, and which, similar to R. B. Fuller's, sought to benefit humanity [5][7].

The characteristics of ephemeral and light used in Otto's structures achieved congruence in the whole project. This was done, not only by the structural system used, but also by the material chosen. The textiles were used for his tensioned roofs, the wood in his grid shells in the Mannheim Pavilion (Figure 13). This later served as an influence for future structures such as those designed and constructed by Shigeru Ban, with whom Frei Otto also had the opportunity to work.

\subsection{Strength and resistance.}

The interest in the grid shells would be complemented by the resistance observed in the molding of a shell with double curvature. This was used for the first time by V. Shukhov. In inverting a network of hanging cables, he observed that the grid and double curvature offered resistance and lightness, without mass [9].

Frei Otto and R. Le Ricolais observe that the mass of the structure is not proportional to the resistance offered. Therefore, the dead loads can become a problem in the construction of the structures. This is due to the fact that the increase in the distance between supports was proportional to the mass of the structural element used. Through the geometric understanding of the existing natural structures, resistance and strength are offered. This is accomplished by avoiding the elements that would be stressed by bending. In Otto's light structures, a greater efficiency is observed with the increase of the tensile strength and decrease in the material.

\section{FREI OTTO \& KENZO TANGE'S ARCHITECTURAL, STRUCTURAL AND URBAN DESIGN INGENUITY: KUWAIT SPORT CENTRE COMPETIITION.}

The Kuwait Sports Centre, together with other important building commissions, bear witness to the process of nation building that Kuwait underwent after gaining its independence from Britain in 1961. Furthermore, the Kuwait Sport Centre scheme proposed by Otto and Tange can be considered as a prelude to their later collaboration in the Artic City Project in 1971 and most importantly, hitherto largely overlooked, this competition project also portrays the essence of their philosophical thinking in the realms of structural and urban design as well as environmental architecture.

\subsection{Post-independent Kuwait's Architecture.}

The Emirate of Kuwait, Abdoullah Al-Salem AlSabah, had planned to host the pan-Arabian Games in 1974 and at the end of 1968 the Ministry of Planning organised an international competition by invitation to design a new large sport complex in its capital: the Kuwait Sport Centre.

The commission and construction of Kuwait's major urban and architectural projects since the early 1960s- including museums, stadiums, and parliament - were steadily introduced to establish legitimacy and architecture became a state apparatus to reinforce the identity of Kuwait as a new, modern and sovereign nation [10] -Kuwait had won its independence from Britain in 1961. Under the supervision of the Advisory Planning Committee (APC), four major buildings were commissioned: the National Museum, the National Assembly, the International Airport and the Kuwait Sports Centre. These are seminal projects as they bear witness to Kuwait as a modern city and also as promoters of the 
modern city networks and its future development.

\subsection{Kuwait Sport Centre Competition Brief.}

With the intention of hosting the Pan-Arabian Games in 1974 the APC set an international competition inviting four experienced and world renowned architecture firms to submit a design proposal for a large sport complex in Kuwait's capital. The invited architects to participate in the competition were: Kenzo Tange (Japan), and Frei Otto (Germany); Felix Candela (Mexico/Spain); Pier Luigi Nervi (Italy) and Morgan, Lloyd, and Jones (UK). These architecture firms had built a world-wide reputation as experts in the design and construction of large sports venues: Nervi with the Olympic Stadium in Rome, 1960; Kenzo Tange with the Olympic Arena in Tokyo, 1964; Felix Candela with the Olympic Sports Palace in Mexico, 1968 and Lloyd, Morgan and Jones with the Houston Astrodome, 1965- the world's largest dome at that time made of metal radial beams spanning $210 \mathrm{~m}$ in diameter [11]. Furthermore, Frei Otto who had joined Tange as the structural consultant for the Kuwait Sport Centre had already become a prominent figure in light-weight structures and was already collaborating in the design and construction of the Olympic Stadium in Munich [12]. Each invited architecture firm was given six months to submit a design proposal and was paid 28, 000 USD.

The architectural programme included six main requirements:

1: A main athletic arena with 40,000 seats $(10,000$ to be covered) and with the possibility to expand to up to 20,000 more; 2: A multisport arena 7,000/10,000 seats (basketball and wrestling); 3: A car park for 10,000 cars; 4: Tennis and hockey pitches for training; 5: Cafeteria and 6: Landscape proposal for the entire site.

However, crucial to this competition was not only the challenge of covering large spans with state of the art structures but to design a network of monumental buildings that would contribute to the modern urban fabric and assist in Kuwait's nation building.

\subsection{Frei Otto and Kenzo Tange's design proposal:}

The project for the Kuwait Sport Centre was the first project in which Tange and Otto would collaborate.
Despite Otto's busy agenda with the Munich Olympic Stadium he travelled to Tokyo where he spent three weeks working with Tange to finalise the design for the Kuwait Sport Centre.

Frei Otto's contribution to the competition was instrumental, he was a pioneer in researching the link between form and structure and he had studied in great detail the self-forming minimal surface particularly on tent and pneumatic structures. Furthermore Otto believed that 'good architecture' possessed intrinsic ecological and aesthetic characteristic and to speak of ecological or sustainable as external or added qualities of architecture was rather redundant. Otto's definition of 'good architecture' did not abide to any trends, fashion, excess or complex theory. It was indeed Otto's honest and assertive approach to nonexcessive and environmental responsive architecture which might have enticed Tange to collaborate with him. Almost fifty years before Otto won the Pritkzer Prize, Felix Candela, one of the most prominent structural artists at the time, had already recognised Otto's achievements in the field of architectural structures and had particularly praised the great contribution of Otto's experimental and research endeavours to further the development of tensile structures. Candela believed Otto was an architect with an extraordinary vision and discipline to create 'structures of the future' [13]. As early as 1952, Otto had already been working on aluminium membranes and he had also built tents for Stromeyer and Zelta in which he observed that "pole supported tents can stand without poles if there is an increased interior pressure' [14]. His research on pneumatics would also push forward the development of a new range of structural systems and materials to achieve new structural forms [15] - always inspired and guided by the close observation of nature.

One of the first projects in which his research on pneumatic structures was applied in order to explore minimal surface form-finding solutions for tent roofs was the Kuwait Sports Centre project where minimal surface of the proposed tent roofs was obtained by experimenting with soap-film models [16]. Complying with the competition's brief, Otto proposed a roof to cover the seats of the main athletic arena and to expand it to the central oasis - in the scheme three main venues were linked by a central oasis (Figure 14). Otto's proposal was very much welcome by Tange who in turn proposed to use similar roofs for the other venues: a multi-sports hall 
and an indoor swimming pool [12].

Environmental considerations in the design proposal included two different techniques to cover the venues, laths would be used to cover partially the nets of the stadium and the pool to provide shading and the indoor arena would be fully covered with aluminium sheets. There is no doubt that Tange \& Otto's experience in previous projects had equipped them with the necessary design and technical knowledge on large sports venues to win the competition, but what certainly gave them an advantage to win this project was their instrumental experience and research on urban design. Otto's great achievements on light-weight structures was complemented with an extraordinary understanding of urban issues and the paramount importance of urban networks to achieve modern urban fabrics. Otto's early works such as 'Occupying and Connecting' as well as his first studies of an Artic City in 1953 were without doubt instrumental in the development of the Kuwait Sport Centre project. Furthermore, Kenzo Tange was a prominent figure in the theoretical and experimental developments of structuralism and metabolism which were materialised in the Tokyo Bay Plan. It is important to mention that Tange had also designed and built the Yoyogi National Gymnasium in 1964, a masterpiece of structural ingenuity and architectural assertiveness incorporating Japanese vernacular architecture into a modern building. Without doubt Tange's experience acquired in the design and construction of the Yoyogi National Gymnasium had provided him with the expertise to respond to the challenges of the Kuwait Sport Centre design brief competition: structural ingenuity, contextresponsive architecture and urban design. Moreover, Tange was also member of CIAM through which he had built an instrumental architectural network in Europe, including Leslie Martin who was part of the jury panel in the Kuwait Sport Centre competition.

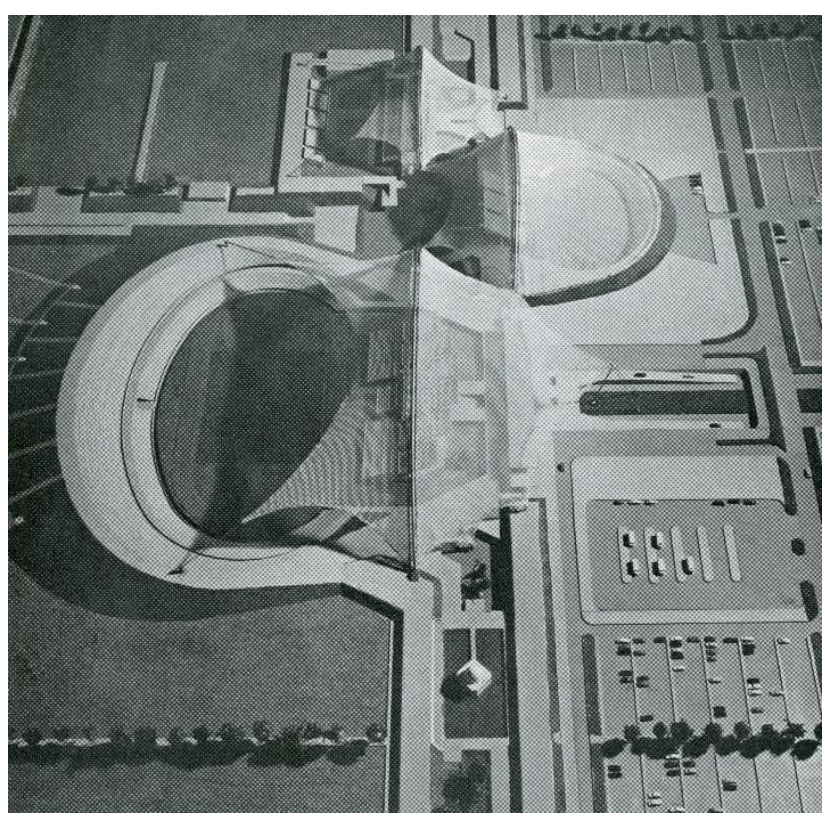

Figure 14. Master plan of the Kuwait Sport submitted by Kenzo Tange and Frei Otto, 1969. [Courtesy of Architectural Design]

The dexterity with which Otto and Tange approached the project is demonstrated on how they conceived the scheme as a network of buildings that extended along a linear scheme which served as a middle-ground hub between the existing city and its new expansion. In particular, the three main sports venues were partially covered and aligned to a pedestrian mall.

Nature was a source of inspiration for both Tange and Otto, not only to find efficient form for buildings but for entire cities and this synergy and holistic approach is evident in the Kuwait Sport Centre. Otto believed that 'primitive architecture was an architecture of necessity' and had no need of excesses, regardless of the utilised material, where structure and ornament are the same and decoration 'make sense if it is essential' [17]. The opening lines of Tange and Otto's report submitted to the APC committee in support to their design scheme [18] are 'in nuce' the conceptual approach to the design project and foremost, a mirror image of their philosophical ideas in architecture. The holistic integration of buildings and roads proposed in the scheme provided a strong platform for the future development of the city where monumentality could portray the spirit and identity of the nation. Without doubt their proposal responded far more holistically to the brief integrating the future urban development of the city and its main arteries with the Kuwait Sport 


\section{Centre site.}

Tange's architectural statement in regard to tradition was orientated to creatively 'elevate both past and future' rather than to create grandiose futuristic schemes or to stagnate in the past [19]. Conversely to Candela's scheme in which rather explicit 'Arabic features' had been incorporated in order to respond to Kuwait's vernacular character, the design by Tange and Otto was an elegant contemporary reinterpretation of the 'Arabic tent' establishing a stronger dialogue with architectural tradition and place making. Furthermore the scheme's response to the spirit of the site was also portrayed in the analogy between the formal expression of the sports venues and the oasis in the desert.

\subsection{Candela, Nervi and Lloyd, Morgan \& Jones project proposals.}

At the time when the Kuwait Sport Centre competition took place, 1969, Felix Candela had already left his construction company Cubiertas Ala in Mexico and a small team of architect friends and former collaborators was set up ad hoc: José Ávila and Juan Antonio Tonda, both architects, had previously collaborated with Candela developing the drawings for the 1968 Sports Palace in Mexico City. Together they developed a project which in the words of Tonda 'had an Arabic style' [20]. Likewise the 1968 Sports Palace of Mexico City Candela's team design proposal incorporated a steel structure of arches resting on parietal fortress-like reinforced concrete walls [20] (Figure 15). Furthermore and as illustrated in the section submitted for the competition (Figure 15) an aluminium net was proposed to generate a smooth and continuous skin to link the arches.

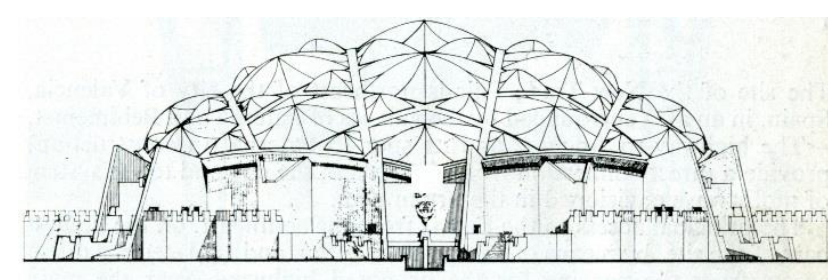

Figure 15. Façade of the Kuwait Sport Centre Stadium submitted by Candela, Ávila and Tonda, 1969. [Courtesy of Architectural Design]

In an effort to respond to the APC's brief requirement of building cohesion in alignment with Kuwait's master plan, Candela's team site strategy included a social forum to link the main stadium with the sports palace and the swimming pool located in the centre but no integration to the larger urban context and foremost, the future city's development, were considered. Furthermore, the proposed car park surrounding the complex (Figure 16) created a visual barrier and diminished the monumental character of the sports complex.

Likewise Candela's team proposed scheme, Studio Nervi's design was devoid of any urban considerations and foremost the proposed architecture, although monumental in size, did not considered the vernacular qualities and architectural tradition of Kuwait. Studio Nervi's proposal had at its core a circular stadium surrounded by the other facilities required in the brief which were orientated according to the four cardinal points: Administrative offices, the athletic arena, football and rugby pitches and the swimming pools.

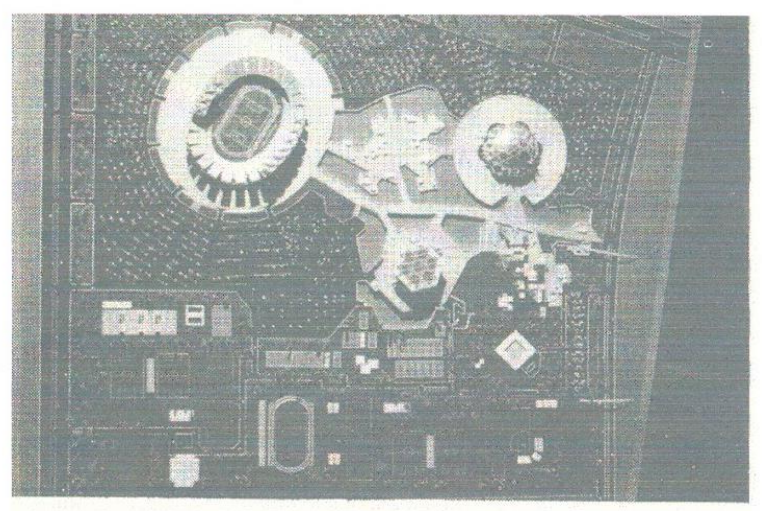

Figure 16. Master plan of the Kuwait Sport Centre scheme submitted by Candela, Ávila and Tonda, 1969. [Courtesy of José Ávila]

The rather over-sized Olympic Stadium circular dome (256 meters) dominated the masterplan. The structural strategy called for a hybrid structure in which the hemispherical dome - a space-frame structure of aluminium tubes patented by the British company, Vickers Ltd., under the name of 'Triodetic' [21] - was independent from the stadium curved stands made of 64 inclined reinforced concrete columns. Interestingly, and contrary to Nervi's philosophy of controlling both design and construction, the design proposal for the Kuwait Sport Centre circular dome was not only influenced by the design of a third party, Vickers Ltd., but if successful there was a high possibility that construction would have been subcontracted to the 
French Company Europe Études [21]. Furthermore and despite the efforts in proposing a controlled environment and louvers, it is rather difficult to imagine how a transparent dome could have worked in the context of Kuwait's climate with temperatures regularly exceeding $45^{\circ} \mathrm{C}$ in summer with a negligible rainfall. On a similar note the design proposal of Lloyd, Morgan and Jones had simply focused on designing large span structures to cover the required sport venues set in the competition brief but no urban or traditional architecture consideration were addressed. Their scheme had a similar orientation and site strategy as that of Candela while their shading strategy was very much in line with that of their earlier Houston Astrodome built project.

\subsection{Concluding remarks.}

The competition jury composed by Prof. Franco Albini (Italy), Prof. Leslie Martin (UK) and Dr. Omar Azzam (Egypt) awarded the first prize to Otto and Tange's project which responded more holistically to the competition brief than any other of the contenders' projects [21]. Otto and Tange's project had a vision beyond the functional requirements of providing and covering large sports venues, their project was empathetic to Kuwait's architectural vernacular heritage as well its future as a modern sovereign nation. Otto's participation in the Kuwait Sport Centre competition represents a significant moment in his professional life as he, the youngest of all contenders, had proved his structural ingenuity to a group of structural designers of international renown: 'Kenzo Tange asked wires to ask if I would participate in an internal competition with such powerful opponents (and friends) as Candela and Nervi' [22]. The pan Arabian Games were cancelled due to the Arab-Isaeli conflicts and none of the competition design proposals were built. Kenzo Tange further pursued this project for the PanAsian Games in Singapore, but it did not resonate as expected, thus the 'idea remained unbuilt' [22].

\section{ACKNOWLEDGMENTS}

Juan Gerardo Oliva would like to thank Jürgen Hennicke and the IL Archive for the photos from Frei Otto included in this paper as well as $D r$. Marisela Mendoza for her meticulous and precise development of the section 6 on Kuwait Sports Centre Competition and Dr. Edwin González for his accurate reflections on Frei Otto as pioneer of sustainable lightweight structures expressed on the sections 4 and 5 of this paper.

Marisela Mendoza would like to acknowledge the architects Juan Antonio Tonda and José Ávila as well as ILEK Archives, University of Stuttgart, Germany for the material made available for this paper as well as for the various correspondences and interviews.

This study is partially sponsored by the General Issues Department for Academic Personnel DGAPA-UNAM, Program PAPIIT IG 400517

\section{REFERENCES}

[1] 2. Internationales Symposium WEITGESPANNTE FLÄCHENTRAGWERKE, Proceedings 2, Sonderforschungsbereich 64, Universität Stuttgart, 1979, pp 14.

[2] Oliva Salinas, J. G., Über die Konstruktion von Gitterschalen, Selbstverlag SFB 64, Mitteilungen, 63/1982, Universität Stuttgart, Germany.

[3] Otto, F., Burkhardt, B., Hennicke J., Gitterschalen, IL 10 publication of the Institute for Lightweight Structures (IL), Universität Stuttgart, Germany, 1974.

[4] Burkhardt, B, Natural structures-the research of Frei Otto in natural sciences, Int. J. Sp. Struct., vol. 31, no. 1, pp. 9-15, 2016. DOI: https://doi.org/10.1177/0266351116642060.

[5] Otto, F., Frei Otto. Working for a better 'earth for mankind'., in Frei Otto: Complete Works, First., W. Nerdinger, Ed. Basel: BIRKHÄUSER, 2005, pp. 9-15. ISBN: 02677768.

[6] Schlaich, J., and Schlaich, M., Lightweight structures, in Widespan Roof Structures, Thomas Telford Publishing, 2000, pp. 177188. ISBN: 0727728776.

[7] Songel, J. M., Frei Otto y el debate sobre la génesis de la forma arquitectónica, EGA. Rev. expresión gráfica Arquit., vol. 15, no. 16, pp. 176-183, 2010. ISSN: 2254-6103.

[8] Drew, P., Frei Otto: form and structure. First. Boulder: Westview Press, 1976. ISBN: 0891585354. 
[9] Otto, F., Trostel, R., and Schleyer, F. K., Tensile structures; design, structure, and calculation of buildings of cables, nets, and membranes. First. Cambridge: The MIT Press, 1973. ISBN: 0262150131.

[10] Alomaim, A., Nation Building in Kuwait 1961-1991, UCLA Electronic Thesis and Dissertations, PhD Thesis Architecture (2016), Permalink: http://escholarship.org/uc/item/91b0909n, last visited: August 2017, p. 42.

[11] Anon, Kuwait Sport Centre, In: Architectural Design, March (1970) p. 136.

[12] Meissner, I., and Möller, E., Catalogue of works. Buildings and Projects 1951-2004, In Frei Otto Complete Works., ed. Nerdinger Winfried, Birkhäuser (2010) p. 271.

[13] Conrad, R., Frei Otto: Structures, Longman, London (1972), p. V.

[14] Walker, D., and Addis, B., Happold: The Confidence to Build, Taylor and Francis eLibrary (2005), p. 63.

[15] Kobayashi. K., Kurokawa. K., Sharp, D., Kisho Kurokawa: Oita Stadium, Oita Japan, Stuttgart [u.a.]: Edition Menges (2002) p. 10.

[16] Glaeser, L., The Work of Frei Otto, The Museum of Modern Art, New York (1972) p.61.

[17] Otto, F., and Rasch, B., Finding Form Towards and Architecture of the Minimal, Deutscher Werkbund Bayern, Edition Menges (2006) p. 13.

[18] Tange, K., and Otto, F., "Report on Sports Center Project: Kuwait' February 1969. Unpublished report, Archive ILEK, University of Stuttgart, Germany.

[19] Boyd, R., Kenzo Tange, Prentice-Hall; Braziller, New York (1962) p. 113.

[20] Personal interview with Antonio Tonda, December 2011.

[21] Mendoza, M., and Cresciani, M., Pier Luigi Nervi, Félix Candela and the Kuwait Sports
Centre Competition in 1968. J. IASS, vol. 54, no. 3, (2013): pp. 199-210.

[22] Otto, F., Kuwait Sports Centre- handwritten notes by Frei Otto, (undated, around 196970), unpublished manuscript, Archive ILEK, University of Stuttgart, Germany. 